and spleen were abolished by colectomy. Fifty-five ileums of patients without Still's disease were free from Staphylococcus citreus.

22. The hands of constipated patients recover from exposure to cold at a very much slower rate than do the hands of healthy subjects.

23. A patient with Raynaud's disease was found to be the subject of chronic intestinal stasis. In his ileum were large numbers of an unusual Gram-positive bacillus and a short streptococcus. Colectomy restored his hands to a normal condition, in which they showed normal reaction after exposure to cold. His ileal flora formed pressor bases from peptone.

The presence of alimentary deformities referred to in this paper was in two instances confirmed at operation by Mr. C. H. Fagge, and in all other instances by Sir Arbuthnot Lane, unless a statement appears to the contrary.

\title{
REFERENCES.
}

1 N. Mitch and J. H. Riffel, Guy's Hosp. Rep. 1012, 223.

N. Mutch, Proc. Physiol. Soc. 1914. Oct.

3 N. Mutch, Quart. Jour. Med. 1914, 427.

4. H. Dale and P. P. Lainiaw, Jour. of Pharmacal. and Exp. Therap. 1912, iv. 1, 75.

\section{RADIOLOGICAL STUDIES OF THE LARGE INTESTINE.}

\section{By A. E. BARCLAY, Manchester.}

To write a paper on the $x$-ray examination of the large intestine would have been comparatively simple a few years ago. One would have been content to take the anatomical structure and deal with it according to the circumscribed views that we inherited. To-day it is different; for we know that the large intestine is but one part of a complex organization, so closely linked together that it is almost impossible to separate out the constituent anatomical parts and deal with them separately. As more and more evidence accumulates to show the interdependence of the whole alimentary tract, the conception of 'watertight' compartments with anatomical boundaries, in the alimentary canal, is disappearing. Here and there we get glimpses of reflex spasms-as, for example, a pyloric spasm from some apparently slight abnormality in the ileocæcal region-that indicate a network of nerve centres, relays, and sub-centres that are as yet beyond our ken.

The physics of osmosis, a long line of test-tube experiments with secretions and ferments, a vague and quite unessential idea of some movement of the stomach and intestine, used to fill the whole field of our conceptions of digestion. Perforce we had to be content with it. In recent years it has become possible to study the mechanics of digestion, and the movements of the food through the tract, and it has become more and more evident that the conditions with which the surgeon is called upon to deal are those that are associated with faulty mechanism rather than faulty digestion; with the result that there is perhaps a tendency to forget that there is a chemistry, as well as a mechanism, of digestion. It is the mechanical factor of digestion that is to-day passing under review; the fons et origo of irregular muscular 
contraction is being sought, and the investigation shows very clearly that the whole musculature of the alimentary tract is linked up by a nervous system that is probably as complex as that of the brain itself; a system subservient to the central nervous system, but also capable of automatically exercising a selective action on ingesta, of calling secretory glands into activity, of preparing the tract for the food that is coming (e.g., emptying the ileum when food is taken into the stomach), and many other functions that we hardly suspect as yet. I know of no subject that opens out a wider field for investigation than this, or one that calls for more careful and accurate observations. It bristles with interlocked problems, some of which have been answered in a dogmatic and quite unscientific spirit by various workers. If $I$ fail in dogmatism - and usefulness possibly - it is because I feel so deeply the responsibility of attacking problems of such vital importance in anything but the most open frame of mind. The profound complexity of the whole mechanism, with its wonderful efficiency, is a thought that should deter any surgeon from mutilation. But there are those who know better than the Maker, who call the large intestine by names that suggest that, if they had the making of man, they would do better. If I cannot go with these, it is because I believe that the Great Architect turned out men fit to live in this world; whose cæca, although apparently insanitary, are yet fulfilling the functions they were intended to perform. That certain rwholesale removals are successful is no proof that they were necessary, but rather that somewhere in the large mass removed lay the cause of the trouble. Some day, these large operations will be unnecessary; but that day is not until we can place a finger on the exact spot where the trouble arises. In the meantime one is astonished, not at the brilliance of the surgery displayed, but by the tolerance of the human body.

"What is one man's food is another man's poison," is an old saying, and expresses the fact that this complex nervous mechanism controlling the digestive tract is not standardized ; that each individual is a separate creation, each bearing outward resemblance to a standard article. Even the gross appearances of the normal stomach vary in such a way that it is only a study of a large number that will give a true conception of the variations that are possible within the limits of the normal. And if such is the case in the stomach, it is even more so in the large intestine, and one is driven to accept wide variations from standard as being quite normal, because function is fulfilled. In fact, the only real test of abnormality that we can apply is that of functional disability; when one has seen such extreme cases as women who are perfectly healthy, and yet defæcate but twice or thrice a month, one is not justified in dogmatizing on the subject of stasis in the large bowel. We have inherited the theory that it is normal to defæcate once a day: if so, all is well ; if not, the anxious mother gives purgatives, and attempts to establish this standard. Nobody is more alive to the importance of keeping the bowels open than I am; but each person is an individual, and it may not be possible for the individual to acquire a twenty-four-hour standard for defæcation; the persistent use of purgatives in such cases is likely in time to lead to real troubles. One sees so many instances of women in whom the opaque meal takes forty-eight hours or more to reach the rectum, in spite of the fact that 


\section{THE BRITISH JOURNAL OF SURGERY}

the whole tract has been cleared out in preparation, that one believes that in many of these the natural habit would be forty-eight hours or more. On the other hand, a habit of even two or three stools a day may be quite natural in some men who live apparently in perfect health. We are so obsessed with this twenty-four-hours' idea that, willy nilly, our children are moulded to it, and undoubtedly it is right for the large majority; but my point is, that there may be very wide variations within the normal limits. If we could accept a universal twenty-four-hour standard, the difficulties of writing on this subject would be comparatively slight, and dogmatism could be indulged; but since each case must be treated as an individual, the evidence deduced from watching

$L$

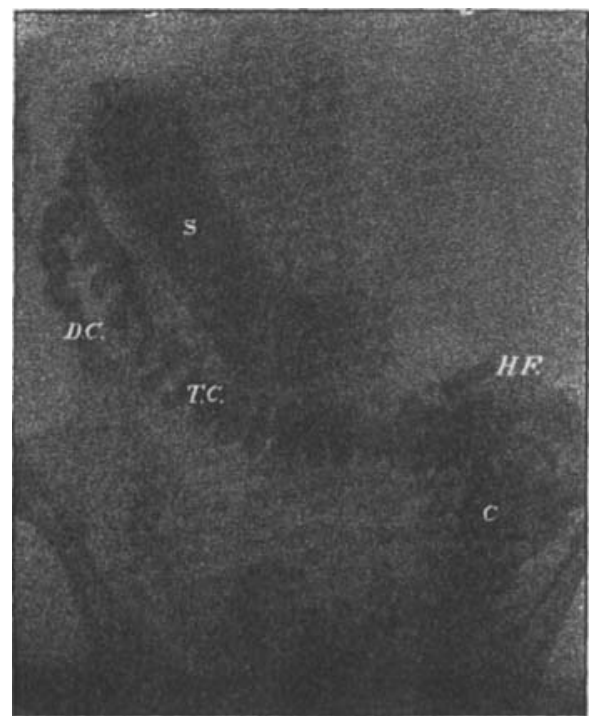

Fio. 349.-Shows Relation of Colon to STOMACF.

Note the hepatic flexure is ptosed, while the eplenic flexure extends nearly to the diaphragm. (s) Stomach; (c) Csecum : (T.C.) Transverse colon; (D.C.) Descending colon; (H.F.) Hepatic flexure. the passage of a standard meal must be most carefully balanced with the clinical picture before deductions are made.

It has been shown that the food passes into the cæcum in part by pressure from behind, 1,2 i.e., that the ileocæcal valve acts as a sphincter, and that its function is not only to prevent regurgitation, but to regulate the flow of chyme into the cæcum. Ileal stasis is, up to a point, a physiological condition, and collections of shadows should be found in the last coils of the ileum in about three hours from the time the food is taken, while the coils should be nearly empty in eight hours. These figures are necessarily very approximate, for the variations in the rate of emptying of the stomach, and the passage of food through the small intestine, vary within wide limits. For instance, to take two extremes: in duodenal irritation one has seen shadows arriving at the ileocreal valve in well under half an hour; whereas, in delayed emptying of the stomach it may be an indefinite time before the food reaches this point. It is therefore very difficult to say what constitutes ileal stasis; not only have we this factor to consider, but also the knowledge that accumulations of fæces in the creum will give rise to back pressure ; and in every case of constipation, when the cæcum is loaded, one will see evidence of ileal stasis. But this form of stasis is readily dissipated by means of a purgative and an enema. Many such cases have been labelled ileal stasis, and published as such in the journals. On enquiry, one finds that these patients have not been prepared, and that no preparation is undertaken because no ileal stasis is found after the bowels have been clcared. Surely, if this is the case, the symptoms cannot be due to ileal stasis, or a simple purgative would invariably relicve the 
condition and cure the symptoms. It is therefore necessary that all patients should be carefully prepared for examination; for if we fail to do so, we may discover a stasis that is in reality nothing but back pressure from cæcal constipation; while, on the other hand, if purgatives are still exerting their influence, there will be a tendency to obliterate any ileal stasis that may be present.

Technique.-The routine I adopt is to give a purgative thirty-six hours before, and an enema on the morning of, the giving of the first opaque meal. After this, apart from the giving of the opaque meal, the patient leads as nearly as possible his ordinary daily life, and observations are made from time to time according to circumstances. When the time available for the work is divided by hospital and private practice, one has to adopt some definite routine for 'double' feeding, and, in my own case, I have the patient prepared as stated, and, at the first examination, watch the filling of the stomach and the manner in which it empties itself. Instructions are then given for feeding on the following day, at such interval before the second examination that one will expect to find the greater part of this second meal in the cæcum. This will vary from three to seven hours, according to the rate of emptying of the stomach observed at the first examination. When the patient is again under observation, one should find in the colon the whole of the food given on the previous day, the head of the shadow being somewhere in the region of the splenic flexure. (When the

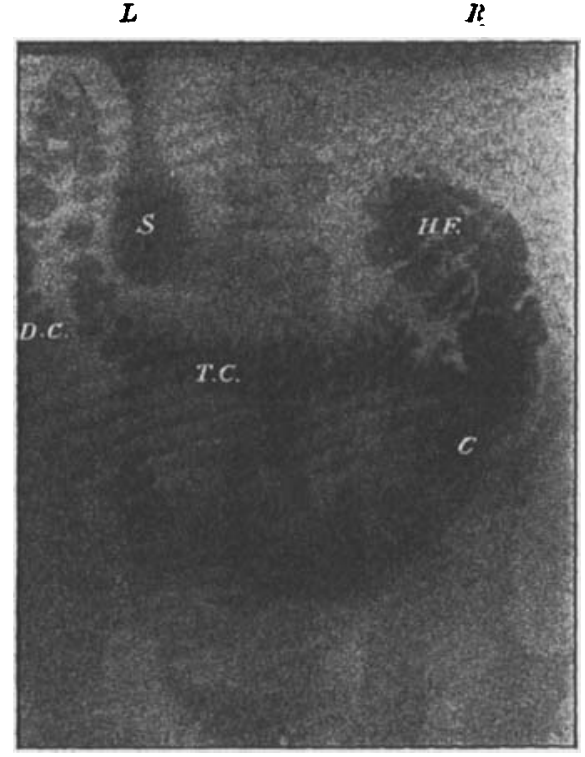

Fig. 350.-Loop of Trasguerse Colon ADEERENT TO THE CECUM.

(S) Stomach; (C) Crecum; (H.F.) Hepatic fexure : (T.C.) Transverse colon; (D.C..) Descending colon. shadow has passed well beyond this point, it is usual for the patient to have had a desire to defæcate, or to have actually passed a motion.) The food given, say seven hours before, should be in the cæcum and ascending colon, with a comparatively small amount in the last coils of the ileum.*

In my opinion it is advisable to use as little of the opaque mixture as is compatible with obtaining clear definition in the picture, and also that the excipient should be a real food. Bread and milk into which the barium sulphate is mixed is what I employ, and it gives good results. Suspensions of opaque salts are, in my mind, to be avoided, for the reason that they quite needlessly introduce a possible source of error. The same applies to the

* Details as to technique are given in book form in The Alimentary Tract, Sherratt \& Hughes, 1914. 


\section{THE BRITISH JOURNAL OF SURGERY}

massive doses of six or eight ounces of opaque salts that are sometimes given. Two or three ounces with each of the opaque meals is ample.*

Anatomy. - The anatomy of the terminal ileum calls for comment : the last four inches look as if they were different in structure, and possibly in function, from the rest of the ileum. This portion does not pursue a tortuous course, but runs more or less straight upwards and outwards to the cæcum. Its calibre is smaller, and the chyme forms a continuous shadow, which is quite different from that in other parts of the small intestine. It looks as if the circular fibres were more evenly developed, and tonic action a miore persistent feature of the muscular contraction. One believes that the whole of this terminal portion is closely associated with the sphincteric and valvular action that is ascribed to the ileacæcal valve itself.

The anatomy of the large intestine, shown radioscopically (Fig. 349), gives a

$\boldsymbol{L}$

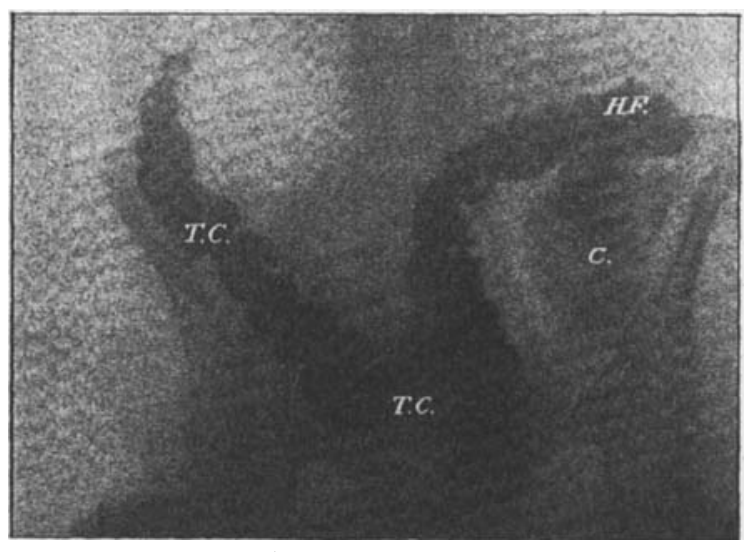

Fig. 351.-Marked Lopp of Transterge Colon adherent in Peluis.

Appendix adhesions. (C) Cæcum; (H.F.) Hepatic flexure; (T.C.) Transverse colon. picture of a more or less uniform tubular organ with regular haustral segmentations, from the cæcum to the pelvic colon. One sees no evidence of any sphincter between the cæcum and ascending colon; in fact, one has developed the habit of thinking of the crecum and ascending colon as one organ. For whenever any tendency to distention and 'sloppiness' is seen, it seems to involve the whole organ as far as the hepatic flexure.

The hepatic flexure is much lower than one expects; it hardly reaches the level of the umbilicus when the patient is standing, and frequently gives the impression of being prolapsed. The splenic flexure ascends to a very high level into the dome of the diaphragm, the actual angle often containing a collection of air that is as closely related to the diaphragm as the furidus of the stomach.

Both flexures look at first sight as if they were acute angles in the gut, but this is not so ; it is due to foreshortening of the two limbs of a $U$-shaped bend.

The transverse colon is far from horizontal. Its general direction is at an angle of $45^{\circ}$ up to the splenic region; but there is almost invariably a loop that drops down to a much lower level, where it is sometimes fixed by adhesions (Figs. 350, 351) ; occasionally it is displaced upwards (Fig. 352).

The descending colon drops straight from the splenic flexure to the iliac crest, and at this point becomes fixed by the peritoneum. In a proportion of

- See The Alimeniary Tract, Sherratt \& Hughes, 1914. 
cases the descending colon' drops down over this fixed point and there is a tendency to kinking. This, I believe, is the only point at which 'kinking,' apart from adhesions, occurs.

The only point about the anatomy of the sigmoid that strikes one is the close relationship that the loaded cæcum and sigmoid may bear to each other. Sometimes they seem to be actually in contact.

Physiology.-The radiographic indications of the physiology of the large intestine suggest a series of problems. The first of these is in the terminal ileum. Someone-Moynihan, I believe-made an epigram to the effect that the most frequent seat of a gastric ulcer is in the right iliac fossa. All surgeons must now appreciate the underlying truth of this. Little by little, facts are coming to light that indicate a very close connection between the ileocreal region and the duodenum. Apart from the surgical evidence as the result of operations on appendices-some. of them apparently healthy ${ }^{3}$-we have radiographic indications that taking food into the stomach tends to make the ileum empty into the cæcum ${ }^{1,2}$; and now $I$ have a series of cases that indicate another type of connection, i.e., a definite ileopyloric reflex, back from the terminal ileum to the stomach:-

In certain cases, duodenal irritation or ulcer type, the stomach began to empty very rapidly, overloading the small intestine. In a short time (say three-quarters of an hour), with a small quantity of food, the stomach was empty. And yet, when a reasonably large meal was given, it was found that, instead of

$\boldsymbol{L}$

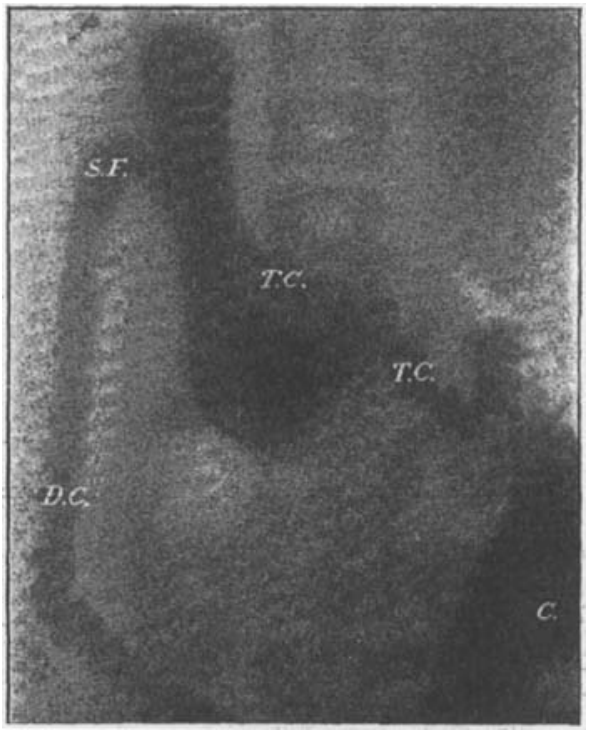

Fig. 362.-Displacement UPWARD OF Trans verse Colon, 8O That IT LIES across THE STOMACH.

No cause for this found at the operation; but in another similar case an old ruptured ovarian eyst was responsible for adhesions anchoring the colon in this position. (C) Cecum ; (T.C.) Trans. verse colon; (S.F.) Splenic Alexure; (D.C.) Descending colon. being empty in the usual four hours, there was actual delayed emptying, and in some cases fully a half was still present after seven or eight hours. On again watching the progress of the food, one noticed that it was, so far as one could determine, when the shadows reached the terminal ileum that this rapid emptying and general activity of the stomach ceased, and in each case there was quite.well-defined fleal stasis, and very little, if any, food seemed to be passing on into the cxcum. These observations give the impression that the terminal ileum is abnormal in some way, and that when once the food gets down to this point it causes a reflex closure of the pylorus and quieting down of the gastric activity-i.e., a message from a nervous centre in the ileocacal region to the centre in the duodenopyloric region, to the effect that as much food has come down as can be dealt with, and a request to shut off supplies. In nearly all these cases one found, at a seven hours' examination, that there was a complete gap between the food in the stomach and that which was collected in a mass behind the 


\section{THE BRITISH JOURNAL OF SURGERY}

ileocreal valve. Those cases that have been operated on have all shown definite evidence of old inflammatory changes in the ileocacal region.*

The importance of this observation is obvious, and throws new light on that curious manifestation-appendix dyspepsia.

Lane's kink I have not recognized radiographically, and I am far from convinced that it is a cause of either ileal stasis or of this ileopyloric reflex.

The ileocæcal valve has been very carefully studied by Case, Hertz, Cole, and others, by means of opaque enemata, and, apparently, it should normally be quite resistant to the injection: no leakage should take place into the ileum. In 16 per cent of cases, 4 however, it is found that the injection does pass through to some extent, i.e., the valvular action is incompetent. In one of my own cases I saw an injection flow quite freely, not only into the ileum, but also into the jejunum; some of it $I$ actually located in the duodenum.+

$\boldsymbol{L}$

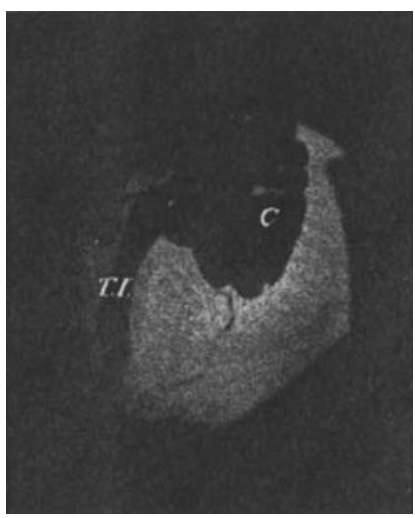

Fro. 353.-Long Appendix hying free.

(C) Cæcum; (T.I.) Terminal ileum.
$\boldsymbol{K}$

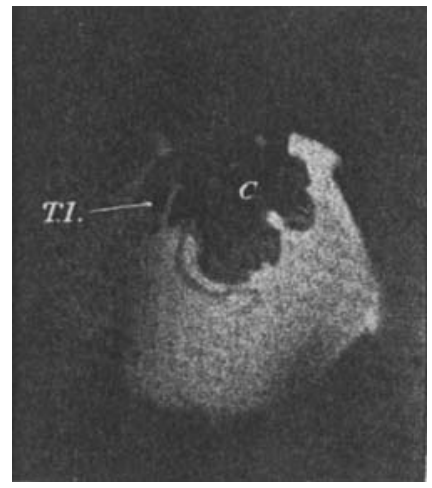

FIG. 354.-APPENDIX ADHEHENT BY MESENTERY TO CECUM ; THE TIF LIFS FREE.

(C) Cæcum; (T.I.) Terminal ileum.

Case states that when this phenomenon is noted radioscopically, the incompetence can be confirmed at the operation by 'milking' the food or air in either direction, and Kellogg' has devised an operation for the repair of the valve or the formation of a new one. As a cause of ileal stasis this defect is well worthy of consideration, and Cole asks if it is likely that the small intestine will tolerate regurgitated fæcal matter without giving rise to symptoms of some kind, probably referred to the stomach. This incompetency of the ileocæcal valve is probably the explanation of the fact that patients sometimes state that they can taste a soap enema. A patient is stated to have actually vomited a part of an oil enema within half an hour.6

The appendix is readily recognized when it is filled with opaque food, and, in a systematic cxamination, one always looks for it with the patient

* This subject is more fully dealt with in The Alimentary Tract, pp. 53 and 98.

t The valve in this case was found to be perfectly competent at the operation, and no cause for the phenomenon was discovered. In fact, the only abnormality noted was a band of adhesions slightly constricting the transverse colon. 
lying down. By using a wooden kitchen spoon, as suggested by Holzknecht, the shadows can be manipulated, and the cæcum can be pushed up out of the pelvis, as described by Case, so that the lower end of the organ is clear away from the shadows of the ileum. If the appendix is filled it is clearly seen, and in one case I had the opportunity of watching various movements that take place therein. It was a very long appendix, nearly six inches at the operation, and it was completely filled. I saw the shadow cut up into five oval beads, and then the organ emptied itself. A few minutes later the shadow again appeared and remained stationary, with the exception of a worm-like writhing movement while the food canalized it, which persisted for a few minutes after it was completely filled. In my cases in hospital, I find the appendix in about 30 per cent of the cases only. Case finds the organ in about 50 per cent of all cases; while George, of New York, gives his figures

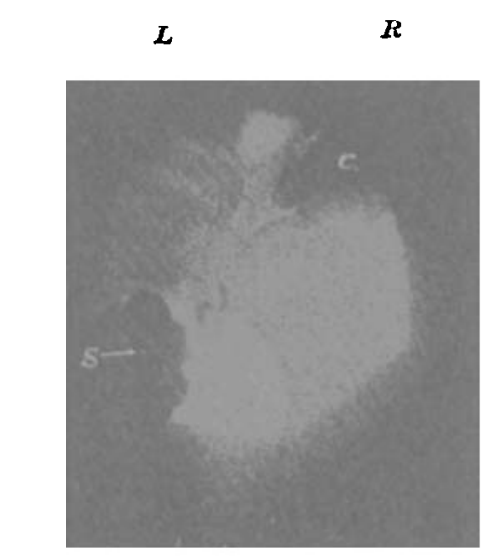

Fig. 355.-LoNg APPENdix wTTH TIP FIXED To SIOXOID.

(c) Cæcum ; (s) Sigmoid.
$\boldsymbol{L}$

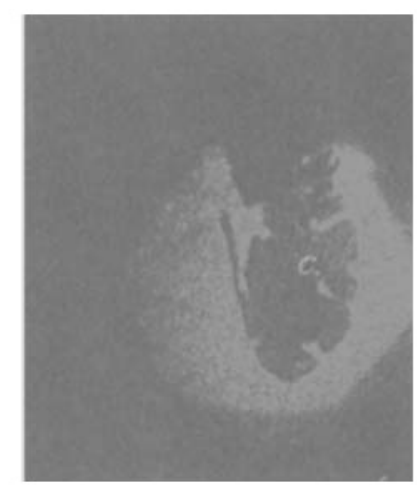

Fig. 356.-ApPendix with Tip Fixed to Terman Ireus.

Adhesions about appendix and duodonal ulcer. (C) Cæcum.

as high as 80 per cent. Case states that he can sometimes 'milk' the food into the empty appendix, an operation in which I have only once been successful.

By manipulation one can tell whether the appendix is adherent or not, and also whether it has a mesentery. Those that point downwards are usually lying free, not bound down (Fig. 353), while those pointing in other directions are often adherent to other viscera (Figs. 354, 355, 356). Apart from making a negative diagnosis when one sees the appendix functioning and lying free, or from detecting adhesions, I have little confidence in making deductions from the appearances as to the presence of trouble caused by the appendix. Leaving out acute cases, my impression is that the effects of appendix trouble are associated rather with referred irregularities of the terminal ileum than with the actual appendix itself, and that in every case where the appendix is removed, it is most important to search out and divide any small adhesions there may be, no matter how insignificant they may appear. 
Movements of the Large Intestine.-From the time when $x$ rays first showed the bismuth-mixed fæces, it was evident that the old theories as to the movements of the large intestine were not correct. The extraordinary thing was that no movement of any kind was seen, and yet from time to time one noted that the head of the column had passed through many inches of the colon between two examinations separated only by a few minutes. Holzknecht7 was the first to see and describe such an actual movement of the freces as would explain this fact. It was apparently a sudden movement, en masse, of the whole column in the colon, and took place in some three seconds. He recorded two observations of the phenomenon out of a large experience, and stated that he believed this to be the normal mode of progress through the large intestine. No further observations, or comments on this observation, were made, and it was not till nearly two years later that the writer saw one case, and happened to obtain radiograms of another, as the movement was taking place. These observations were published, together with the radiograms $; 8$ but it was not until $\mathrm{Hertz}^{9}$ studied the phenomenon systematically that this somewhat revolutionary theory became more or less established. Taking advantage of the fact that the call to stool usually follows close after a meal - the gastrocolic reflex-he made a series of observations on medical students, and confirmed the Holzknecht theory. He saw the movement actually taking place in three of the patients so examined. In all, I have seen it take place some ten times, and am absolutely convinced that it is the natural and normal movement. In three students whom we examined as they ate their breakfast and for a time afterwards, Mr. J. Morley and I saw the movement in one case most perfectly; and in another instance we happened to look at the patient just as the movement was about over. Jordan has also recorded observations on these movements; but Case's report before the 17th International Congress of Medicine is the most extensive and scientific treatise on personal observations that $I$ have seen.10

There is not, so far as I know, any theory, except this of 'mass' movement, that will explain the facts as we see them. All the observers agree that, without subjective sensations of any kind, the haustral segmentation disappears, and the whole mass rushes suddenly--in three seconds, Holzknecht suggested-through a length of colon. In all my cases it happened that the head of the column was in the region of the hepatic flexure, and when the movement finished, the head of the shadow had passed on to the splenic flexure or further.* The whole process is over in a very short time, and the haustral segmentation, and general picture of still life, are almost immediately restored. My impression is that the perfectly natural movement is somewhat slower; at any rate it has appeared to be so since I had my patients prepared by purgatives thirty-six hours before the first meal, i.e., sixty hours before one expects to observe the large bowel. In one instance I timed the passage from the middle of the transverse colon to the pelvic brim as fifteen seconds; but in all

* I have recently seen a case in which a portion of the shadow was cut off from the ascending colon, and traversed the whole length of the colon into the sigmoid. When the movement was over, a slight antiperistaltic 'mass' movement took place, in the nature of a rebound, and part of the shadow again returned through the iliac colon to just above the iliac crest. The whole movement occupied about ten seconds. 
the other cases the passage was so unexpected that it was almost completed before one had time to realize what was happening. The mechanism appears to be: (1) A relaxation of the tonic action of the muscular coats; followed by (2) A big peristaltic wave that sweeps the whole contents along. This movement probably occurs some three or four times a day.

Incidentally, it is interesting to note that the firm and solid appearance of the colon shadows, both on the plate and also on palpation, is due to the tonic action holding the more or less fluid fæces in definite form.

Constipation.--I see no alternative but that we accept this en masse theory of the movement of the food through the large intestine; and such being the case; we must revise all our conceptions, not only of the normal but also of the pathological. The movements certainly tend to occur after a meal, quite shortly after it is eaten-Hertz's and my own observations were all made at breakfast time, as being the most likely, and we were both successful in seeing the phenomenon; while in ordinary routine work one does not see evidence of movement during the examination in more than a very small percentage of cases : in private practice, in the afternoon, $I$ have only once seen any of the movements, and comparatively seldom noted that any alteration has taken place between the observations. The call to stool does not necessarily follow one of these movements. In fact I have found it entirely absent, although in two of the cases the rectum was already full.

From his observations on students, Hertz1l suggested that the average normal times in which food should reach various points were :--

\begin{tabular}{|c|c|c|c|}
\hline Cæcum & $\ldots$ & $\ldots$ & $4 \frac{1}{2}$ hours \\
\hline Hepatic flexure & & & $6 \frac{1}{2}$ \\
\hline Splenic flexure & $\cdots$ & $\cdots$ & 9 \\
\hline Brim of pelvis & $\ldots$ & $\ldots$ & 11 \\
\hline
\end{tabular}

He is insistent on the fact that these are only average times, and wide differences are possible even in perfectly normal subjects. If we accept this ' mass' movement, occurring some three or four times a day, as the normal, it is evident why these wide variations are possible.

Constipation has been defined by Hertz and others; but. holding the views I do, I would rather leave out any definition; each case is an individual, and this must not be lost sight of for the sake of making a definition. One sces patients who are always out of health if a daily action is not obtained; while one has also seen health regained when patients have ccased to worry the intestines into daily actions, and reverted to a habit of twice a week. My own experience in the study of these cases indicates that there are two, and only two, real seats of stagnation in the large intestine (apart from kinks and adhesions), namely the cæcum and the rectum. Of these, the rectal stagnation is the most frequent, and to it Hertz has given the name of dyschesia. It is in reality a fault of defæcation rather than a true constipation. In these subjects it is extraordinary to see the way in which the shadows accumulate and form great masses in the rectal ampulla without any call to stool being felt (Figs. 357, 358). The rectum is sometimes ballooned out to a great size, and is presumably atonic. When the bowels have been moved one finds that it is only a part of this shadow that has disappeared. 


\section{THE BRITISH JOURNAL OF SURGERY}

But in constipation proper, the delay is nearly always in the cxcum and ascending colon, and these portions remain filled for days at a time, in spite of the fact that some of the contents may have moved on to various portions of the colon; in other words, there is a defect in the ' mass' movement, a defect not of one part of the colon, but of the mechanism. The position of the head of the shadow is not necessarily an index to the site of the portion of the gut that is responsible for the delay. One believes rather that the constipation is more likely due to some fault in obtaining a more or less fixed point, ${ }^{*}$ or a temporary sphincter at some point, from which to work, than to a defect in the movement itself.

One has never seen, nor are there any records to show, that this movement takes place in the cæcum itself. One has often seen movements in the lower part of the cæcum of a peristaltic nature, and it is possible that these should be sufficient to raise the food to a position in the ascending colon in

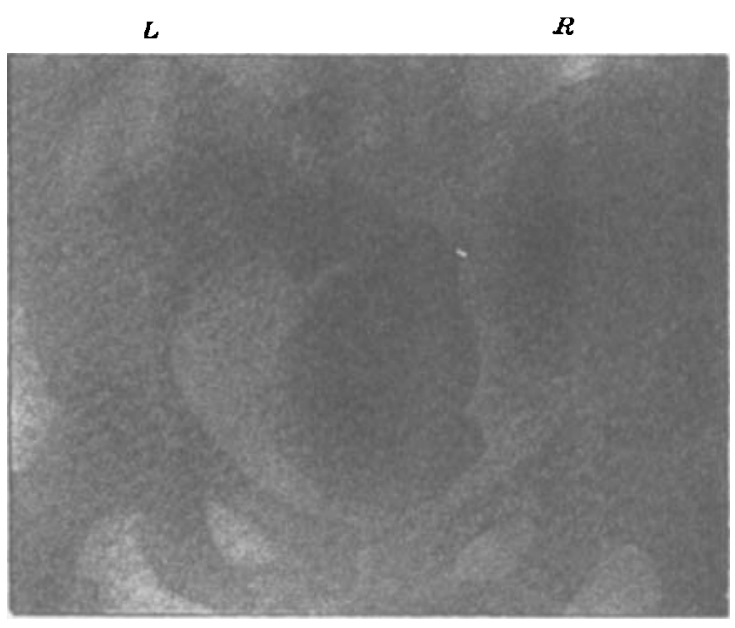

Fig. 357.-Dilated Rectal Aupulga is a Case of Drschesia. which this 'mass' contraction can eatch hold and carry the food along. As the result of his researches in comparative anatomy, Keith believes that there is some form of sphincter between the cæcum and ascending colon. Possibly, although one sees no radiographic indications of it in the ordinary course of events, there is some sphincter, as he suggests, and its function may be to prevent regurgitation when the 'mass' movement is in progress. In support of this hypothesis there are several observations: one has

never seen the cæcum empty suddenly between two observations, nor has the 'mass' movement of the shadow been observed to clear out the cecum. On the other hand, one has frequently observed large shadows left in the cæcum while the contents of the hepatic flexure and transverse colon have passed far on towards the pelvic colon. Moreover, although the large intestine is always swept clean (except for definite scybala possibly), there are often traces of the opaque meal left in the crecum for days--i.e., it is not swept clean.

This 'mass' theory is so unparalleled in the human body that one hesitates to go any further than this brief suggestion of the normal. One finds widely ballooned colons and greatly narrowed colons-that is, apparently atonic and hypertonic types-and these have been described as the causes of constipation; but I doubt whether they are. Rather, I would suggest, they indicate the condition of the colon between the movements, for I happen to have seen

* A point d’appui. 
the 'mass' movement sweep the shadow along both types of colon, and in both the movement was perfectly effective in displacing the contents. The part played by the cæcum is not clear ; but if my deductions are correct, this portion of the large gut has a separate mechanism or peristalsis for mixing the contents and feeding them into the ascending colon, preparatory to the occurrence of the 'mass' movement.

Further Note on Constipation.-Since writing the above, I have on two occasions noted the formation of a definite constriction-a point d'appui -such as I suspected was recessary for the efficiency of the mass movement. In each case it was near the hepatic flexure, and was not evident until this was palpated out with the spoon. ${ }^{*}$ I am not absolutely certain on the point, but believe that the sphincter was formed after palpation of the cæcum in the exploration of the appendicular region. In both instances the colon distal to the constriction lost its haustral segmentation, and the contents seemed to back up to the point d'appui, as if forming a mass ready to be propelled onwards when the 'mass' movement took place. In both cases a strong ' mass' movement occurred within half an hour, but I did not actually see it. In one instance the whole column on the distal side of the point d'appui was swept along ; while in the other about half of it was left behind. In the latter case, however, the colon did not look healthy, and, in fact, there was mucous colitis. These two cases are, at least, distinctly suggestive that my

L $R$

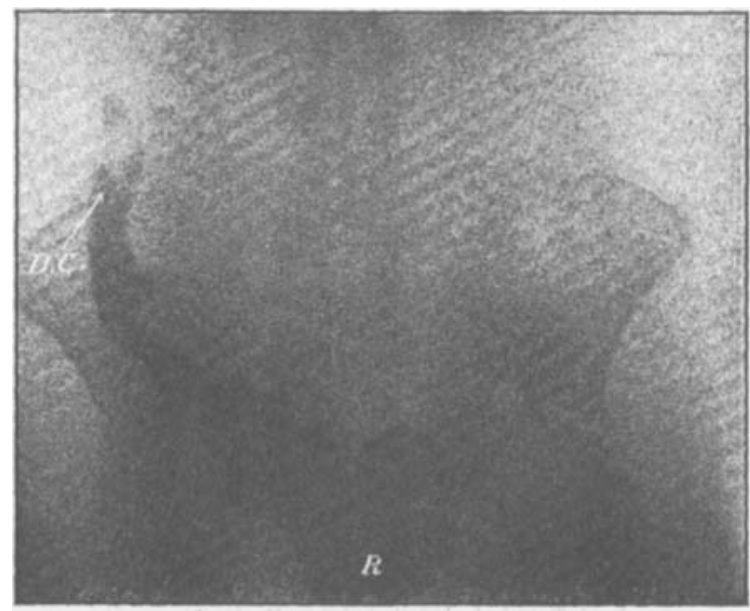

Fic. 338.-Case of Drschesia : 72 hours after food, rectum full, but no call to stool.

(R) Rectum; (D.C.) Descending colon. hypothesis is correct, and I am now examining the hepatic flexure both before and after palpation of the cxcum in order to obtain more evidence on the point.

It is too early to make a definite statement, but I am becoming more and more convinced that the keystone to the efficiency of this movement of the large intestine lies in the competence of the point d'appui, and that it is on the competence of this temporary sphincter that the natural action of the bowels depends. Inversely, the failure or incompetency of this valve is responsible for the constipation, i.e., the ineffectiveness of the 'mass' movement when it

- I have now seen the formation of a point d'appui in the splenic end of the transverse colon. The haustral segmentations first disappeared, leaving a fat. sausage-shaped mass in which a constriction developed after a few minutes. Shortly after the formation of this sphincter, the mass distal to it started and moved comparatively slowly, in about 44 seconds I should say, round the splenic flexure and down to the rectum.

voL, $11 .-$ No. 8 . 
takes place. For if there is no point d'appui the fæces regurgitate into the cæcum, possibly giving rise to the sloppy cæca that we recognize and think of as the cause of constipation. Not only so, but in time one would expect this to lead to inefficiency of the ileocæcal valve.

Moreover, if the 'mass' movement is not effective, there is nothing except the comparatively feeble movement of the cxcum to propel the food through the large intestine, and when the movements take place, they propel the fres in both directions, i.e., the mass in the creum has to act as an inefficient point d'appii.

The subject is full of difficulty; not only are the observations few and far between, in spite of the vast number of patients examined; but also because the whole new conception is revolutionary, and alien to the traditional line of thought-it would be easier if we had not been brought up on armchair conceptions of what takes place, for unconsciously we attempt to make our observations fit in with our preconceived notions.

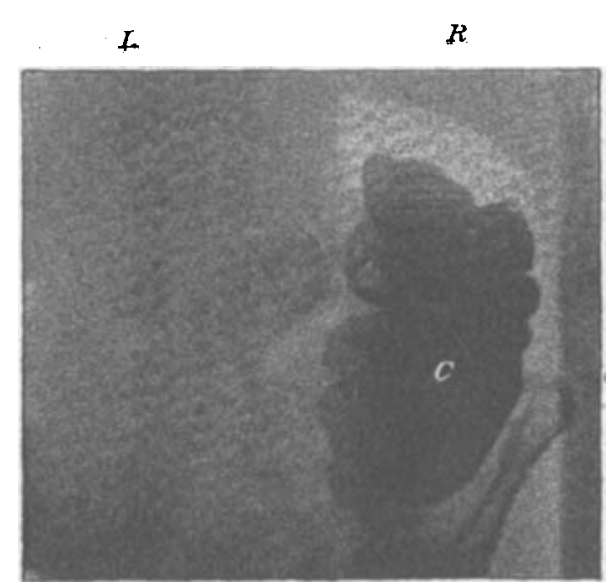

Fio. 360.-Dilated Cacum in a Case of Neoplasm of the Trangverse Colon. (c) Crecum.

Other Movements of the Large Intestine. - Antiperistalsis is also stated to occur in the large intestine; Case gives incontrovertible proof of it, and it is likely that it can occur in the normal healthy subject. In fact, to-day, I have actually seen it occur in a small way after a 'mass' movement had taken place. It is probable that this movement is exactly parallel to the usual forward 'mass' movement, but occurring in the opposite direction. One does not actually sec any such movement on injecting an enema, but even a pint will be carried back to the cxcum in most cases.

Besides the 'mass' movement, one sees from time to time changes in the shape of the haustral sections of the large intestine, especially in the distal colon. It is not at all a marked movement, and has probably no connection with the progress of food along the intestinc. Presumably it is connected with digestion, and acts by churning.

Rieder described 'large pendulum' movements, which appear to be much the same as the smaller haustral churning of which we frequently obtain evidence. Case states that in every instance he has seen of the larger movement, it has been the precursor of a large 'mass' movement.

Neoplasms. - Turning now briefly to the organic lesions of the large bowel, one finds that it is only when there is obstruction of the ascending and first part of the transverse colon that one can obtain definite evidence from feeding the patient. In these cases one gets great ballooning of the cxcum and ascending colon (Fig. 359). But in growths or other obstructions occurring beyond this region, there is only one method of investigation in early 
cases, and this is by means of the opaque enema delivered from a glass tunnel-dish through a tube. Watching the course of the opaque injection we can see where it is obstructed and the stream narrowed (Fig. 360), and with the aid of palpation we can, as a rule, form a very good idea as to the nature and extent of the lesion that is causing the trouble. In this, as in the opaque meal work, it is very important to confirm observations by re-examination, for spasmodic contractions may be most misleading. Especially is this the case with the upper sigmoid, and on one or two occasions I have been misled. When an obstruction is noted at the pelvic brim, I have found it advisable to lay the patient on his face, a proceeding that sometimes allows the injection to pass on quite freely.

In advanced cases, however, one nearly always finds collections of air and liquid in the distended bowel behind the obstruction. But, as already suggested, it is only in advanced cases that this ballooning of the bowel occurs. It is in this type of case that evidence of antiperistalsis is most often noted.

It is interesting and instructive to notc that the food given by the mouth seldom forms heavy shadows behind an organic lesion in the distal large intestine until the obstruction is very far advanced; in fact, the head of the shadow seldom reaches the obstruction, and more often than not the shadow is comparatively thin, as though the colon xvere hypertonic in its efforts to overcome the obstruction; it is only when this hypertonic state gives way that the gut behind the obstruction becomes distended and filled with fæces.

Palpation of the loaded colon will give the clue to the presence of Jackson's membrane, adhesions; kinks, and other abnormalities that occur; but of these I have not time to write at present.

After excision of the cacum and a portion of the colon, one finds the remains of the colon apparently normal, except as regards disposition. The striking feature is the absence of any definite division between large and small intestines. In fact, in the few cases $I$ have had the opportunity of following, a portion of the ileum seemed to have taken on the $x$-ray appearances of the colon.

My thanks are due to the staff of the Manchester Royal Infirmary, and especially to Mr. A. H. Burgess, for the use of their cases and for the support they gave in carrying out investigations. 


\section{CONCLÚSIONS.}

1. That the large intestine is only one part of a closely linked-up system.

2. That very wide variations, both as regards anatomy and physiology, are compatible with perfect health.

3. That the ileocæcal region is in very close association with the duodenopyloric region. There is evidence of two separate reflexes between the ileocæcal valve and the pylorus, i.e., one from the stomach to the ileocæcal valve, and another from the ileocxcal valve to the stomach, the latter (the ileopyloric reflex) being responsible for appendix dyspepsia.

4. Ileal stasis is, up to a point, physiological. Pathological ileal stasis is usually associated with adhesions in this region, most frequently appendicular in origin.

5. In all these examinations it is essential to prepare and cxaminc patients on a routine plan. A scheme that includes 'double' feeding is useful.

6. The appendix can be seen in a certain proportion of cases, and, by palpation, it can be detected whether it is fixed or lying free.

7. The normal movement of fæces through the large intestine is by 'mass' movement, in which a large column is moved through a long section of the colon in a few seconds; these movements take place probably some three or four times a day. The "mass' movements do not occur in the cæcum.

8. Constipation occurs as the result of stagnation: $(a)$ In the sigmoid and rectum, i.e., inefficient defæcation, or dyschesia; and $(b)$ In the cæcum, constipation proper.

9. Constipation proper is probably the result of a defect in the mechanism of the 'mass' movement. It is suggested that for the efficiency of this movement it is necessary that a sphincteric contraction should be present. The competency or otherwise of this sphincter, or point d'appui, determines whether the 'mass' movement, when it occurs, propels all the fæces forwards, or sends some of them back into the cæcum. The large, sloppy cæcum is the result of this inefficiency, and not the cause of constipation.

10. The opaque meal seldom gives information as to early neoplasms of the large intestine-it is only after the bowel becomes distended that information is obtained in this way. All suspected cases of neoplasm of the large bowel should be investigated by means of the opaque enema.

\section{REFERENCES}

1 CAse, J. T., Amer. Quarterly of Röntg., 1912, Nov.

2 Hertz, A. F., Journ. of Phys., 1813, Oct. 17.

s Suerren, J.," "Relation of Appendicitis to Dyspepsia," Brit. Jour. of Surg., 1914, i, April.

- Case, J. T., 17fh Internat. Congress of Medicine, 1913.

"Kelloga, "Surgery of the Ileo-creal Valve," Surg. Gym. and Obst., 1913.

5 Cantani, Virchow's Jahresbericht, 1879, ii, 180.

7 Holzknechi, Münch. med. Woch., 1909, No. 47.

a Barclay, A. E., Arch. Röntg. Ray, 1912.

- Hertz, Jour. of Phys., 1913, Oct. 17.

${ }^{10}$ CASE, J. T., "X-ray Observations on Colonic Peristalsis, etc." 17th Inlernal. Congress of Medicine, 1913.

1 Hertz, Constipation and Allied Inlestinal Disorders, London, 1009. 